\title{
O DOCUMENTÁRIO DE DIVULGAÇÃO CIENTÍFICA: TIPOS E POTENCIALIDADES DE USO NO ENSINO DE CIÊNCIAS
}

\author{
EL DOCUMENTAL CIENTÍFICO: TIPOS Y USOS POTENCIALES \\ EN LA ENSEÑANZA DE LA CIENCIA
}

\section{THE SCIENCE DOCUMENTARY: TYPES AND POTENTIAL USES IN SCIENCE TEACHING}

\author{
Aldo Aoyagui Gomes Pereira ${ }^{1}$ \\ Silmara Rodrigues Domingues ${ }^{1}$ \\ Aline Rodrigues de CARVAlHO ${ }^{1}$ \\ Instituto Federal de Educação, Ciência e Tecnologia (IFSP), \\ Piracicaba/SP - Brasil ${ }^{1}$
}

Resumo A partir de atividades realizadas com licenciandos cursando a disciplina Práticas do Ensino de Física, empregando documentários de divulgação científica, verificamos o potencial desses recursos para o desenvolvimento de práticas em disciplinas científicas do ensino médio. Ao mesmo tempo, identificamos que pesquisas sobre o uso do audiovisual em sala de aula apontam que os principais objetivos dos professores, ao usarem esses recursos em suas aulas, são: motivação, visualização e reforço de conteúdos científicos. Neste trabalho, sugerimos outras formas de utilizar documentários de divulgação científica em sala de aula, tendo como apoio teórico-metodológico os modelos do déficit, contextual e de participação pública de divulgação da ciência. Selecionamos cinco documentários produzidos pela $\mathrm{BBC}$, PBS e History Chanel e sugerimos atividades e questões endereçadas às disciplinas científicas do ensino médio. Entre elas, destacamos o potencial desses recursos para a discussão de questões envolvendo a natureza da ciência e debates sociocientíficos. Além disso, discutimos a relevância de se trabalhar as representações de ciência contidas em recursos audiovisuais, principalmente numa sociedade como a nossa, em que a principal fonte de informação a respeito da ciência, ao longo da vida desses jovens, serão as diversas manifestações da mídia.

Palavras-chave: Documentários; Divulgação da Clência; Educação em Ciências; Ensino MÉDIO. 
Resumen A partir de las actividades realizadas con docentes pre-servicio inscritos en la disciplina Prácticas de Enseñanza de Física, utilizando documentales de ciencia, verificamos el potencial de estos recursos para el desarrollo de prácticas en las disciplinas científicas de la escuela secundaria. Al mismo tiempo, identificamos que la investigación sobre el uso de audiovisuales en el aula muestra que los principales objetivos de los profesores de ciências, al usar estos recursos en sus clases, son: motivación, visualización y refuerzo de los contenidos científicos. En este trabajo, sugerimos otras formas de utilizar documentales de ciencia en el aula, teniendo como soporte teórico y metodológico los modelos de déficit, contextuales y de participación pública de Comunicación de la Ciencia. Seleccionamos cinco documentales producidos por la BBC, PBS y History Channel, y sugerimos actividades y preguntas dirigidas a las disciplinas científicas de la escuela secundaria. Entre ellos, destacamos el potencial de estos recursos para la discusión de temas relacionados con la naturaleza de la ciencia y los debates socio-científicos. Además, discutimos la relevancia de trabajar las representaciones de la ciencia contenidas en los recursos audiovisuales, especialmente en una sociedad como la nuestra, en la que la principal fuente de información sobre la ciencia a lo largo de la vida de estos jóvenes serán las diversas manifestaciones de los medios de comunicación.

Palabras clave: Películas documentales; Comunicación de la Ciencia; Enseñanza de las Ciencias; Escuela Secundaria.

Abstract From activities carried out with pre-service teachers, enrolled in the discipline Practices of Physics Teaching using science documentaries, we verified the potential of these resources for the development of practices in scientific disciplines of High School. At the same time, we identify that research on the use of audiovisual in the classroom show that the main goals of science teachers when using these resources in their classes are: motivation, visualization, and reinforcement of scientific contents. In this work, we suggest other ways of using science documentaries in the classroom, having as a theoretical and methodological support the deficit, contextual and public participation models of Science Communication. We selected five documentaries produced by the BBC, PBS and History Channel and suggested activities and questions addressed to High School scientific disciplines. Among them, we highlight the potential of these resources for the discussion of issues involving the nature of science and socio-scientific debates. In addition, we discuss the relevance of working the representations of science contained in audiovisual resources, especially in a society such as ours, in which the main source of information about science throughout the life of these young people will be the various manifestations of the media. Keywords: Documentary films; Science Communication; Science Education; High School. 


\section{INTRODUÇÃO}

As reflexões, considerações e sugestões descritas neste trabalho, começaram a se delinear no segundo semestre de 2012, quando atuamos como professor da disciplina Práticas do Ensino de Física em um curso de licenciatura em Física de uma Universidade Pública do Estado de São Paulo. Nesse curso, após a realização de atividades com Documentários de Divulgação Científica (DDC), surgiram discussões e sugestões informais entre o professor da disciplina e os futuros professores de Física sobre as potencialidades de se usar esses recursos nas aulas de disciplinas científicas no Ensino Médio (EM) (PEREIRA, 2017). Após uma revisão bibliográfica, tanto em âmbito nacional quanto internacional, acerca das relações entre os recursos audiovisuais e a sala de aula, surgiram importantes considerações sobre as formas de se usar esses recursos no espaço escolar. Apontamos aqui algumas dessas considerações, destacando a importância de refletirmos a respeito delas, quando escolhemos e realizamos atividades com recursos audiovisuais no ensino de Ciências.

Inicialmente, apresentamos um breve panorama de pesquisas realizadas no âmbito do uso da Divulgação Científica (DC) nos espaços formais de ensino. Discutimos três modelos de DC, relacionando-os aos possíveis usos de recursos audiovisuais em sala de aula no ensino de disciplinas científicas. Consideramos aqui que quando falamos sobre disciplinas científicas, estamos nos referindo às disciplinas de Ciências do Ensino Fundamental II e às disciplinas de Física, Química e Biologia do Ensino Médio (EM). No entanto, como sugerimos ao longo deste trabalho, nada impede que as atividades propostas sejam efetuadas numa perspectiva multidisciplinar, incluindo outras disciplinas do EM. Particularizamos aqui o uso de Documentários de Divulgação Científica (DDC), descrevendo os principais tipos e estilos produzidos atualmente e a pontencialidade desses para desenvolvermos atividades em sala de aula. Por fim, selecionamos alguns títulos produzidos pela British Broadcasting Corporation (BBC), Public Bradcasting Service (PBS) e do History Channel e abordamos algumas sugestões de uso desses recursos, tendo em vista os modelos de DC exibidos.

Muitos estudos na área de Educação em Ciências apontam para a necessidade de uma integração entre os conhecimentos de ciência disseminados nos espaços informais (museus, notícias, internet, filmes, documentários etc.) ao espaço formal de ensino (escola) (MCCLUNE; JARMAN, 2012; ACHIAM; NIELSEN, 2016; JIDESJÖ, 2010; FALLIK; ROSENFELD; EYLON, 2013; FERREIRA; QUEIROZ, 2012; MARANDINO, 2015; ALMEIDA, 2015). Entre os motivos que justificam essa integração, estão aqueles relacionados ao uso da DC com o objetivo de diversificar as aulas de Ciências no ensino fundamental e médio. Nesse sentido, o uso da DC em sala de aula pode contribuir para a promoção de outras estrátegias de ensino, além das tradicionais que priorizam a transmissão de conhecimentos científicos factuais e linguagem matemática na resolução de problemas.

Estudos realizados no contexto brasileiro a respeito de como os audiovisuais e Textos de Divulgação Científica (TDC) são usados em sala de aula evidenciaram que essa parceria se dá, em grande parte, para motivar, sensibilizar, visualizar e reforçar conteúdos científicos (ARROIO; GIORDAN, 2006; REZENDE, 2008; SANTOS; ARROIO, 2009; RE- 
ZENDE; PEREIRA, VAIRO, 2011; GUERRA; MORAIS, 2013; RAMOS; SILVA, 2014; PEREIRA, 2017).

Nesse contexto de uso da DC em sala de aula, o audiovisual é visto como recurso didático, cujo discurso sobre a ciência é naturalizado e aproblemático. Uma possível consequência disso é que, em vez de promover uma curiosidade nos jovens em saber mais a respeito de ciências, ou decidirem pelas carreiras científicas, alguns gêneros audiovisuais, ao apresentarem uma imagem glamorosa e espetacular da ciência, com acesso a poucos, produto do esforço individual de alguns gênios, podem causar um distanciamento em relação às carreiras científicas, pois "numa ciência feita por heróis não há lugar para pessoas comuns" (CHAVES, 2012, p. 84). Outra consequência é que, uma vez que a mídia pode ser considerada uma das principais fontes de informação sobre ciência para os jovens que não seguirão carreiras científicas, é fundamental que procuremos, como formadores de professores e professores de ciências, desenvolver oportunidades para que os estudantes desenvolvam a argumentação científica e saibam realizar a leitura crítica fundamentada das representações de ciência e de cientista veiculada por esses meios (RAMOS; SILVA, 2014; REID; NORRIS, 2016). Como apontado por Terrazan (2007, p. 160):

\footnotetext{
Nas últimas três décadas, os avanços vivenciados nos campos econômico e científico-tecnológico foram significativos e impactantes, mas também acompanhados de grande produção de desigualdades sociais e de efeitos contraditórios ambos igualmente significativos, e o uso de mídias diversificadas no espaço escolar contribuem para um diálogo profícuo destas questões (TERRAZAN, 2007, p. 160).
}

Em um trabalho de 2011, por exemplo, Grace Reid investigou como um gênero de DDC conhecido como dramadoc, pode contribuir para informar dois grupos focais, um do Reino Unido e outro do Canadá, sobre os debates sociocientíficos envolvendo a clonagem humana. O documentário usado pela pesquisadora, intitulado "Se a clonagem pudesse nos curar" (SE A CLONAGEM, 2004), combina elementos ficcionais, entrevista com cientistas e especialistas em questões éticas, além de trazer informações factuais a respeito do conceito de clonagem. De acordo com a pesquisadora, o dramadoc usado cumpriu sua função em informar os participantes do estudo acerca da problemática em questão, além de instrumentalizá-los para a tomada de decisão fundamentada sobre os limites e possibilidades da pesquisa em clonagem humana (REID, 2011). Concordamos com McClune e Jarman (2012), Reid e Norris (2016) e Ramos e Silva (2014), ao alertarem os formadores de professores e professores de ciências sobre a importância de se discutir as representações de ciência na escola, considerado como local privilegiado para a formação de leitores de ciência na mídia.

Para isso, a mediação do professor no trabalho com mídias em sala de aula é fundamental, pois algumas narrativas produzidas por esses meios, semelhante ao discurso da ciência produzido na escola (DUSCHL, 1990; ALMEIDA, 2004), podem fazer que os estudantes aceitem as conclusões científicas como absolutas (e não passíveis de argumenta- 
ções) ao privilegiar uma leitura única, o que Duschl (1990) chama de final form science. Dependendo de como é usado no ensino, o documentário pode "ao invés de alargar a imaginação, provocar o conforto paralisante da impotência ou do conformismo, ou seja, o oposto do que almejam a educação, a divulgação científica e o cinema" (TAVARES, 2015, p. 90).

\section{Modelos de divulgaÇão da CiênCIA: Propostas para A SAla de AUla}

Quando pensamos na forma como as atividades envolvendo a Divulgação Científica (DC) em sala de aula são realizadas, notamos que a estratégia prevalente é o modelo do déficit (STURGIS; ALLUM, 2004; JARMAN; MCCLUNE, 2007). Nessa perspectiva, assim como nas aulas tradicionais de Ciências na escola, as atividades efetuadas com Documentários de Divulgação Científica (DDC) têm como principal função transmitir para os estudantes os significados, definições e produtos da ciência e tecnologia, ou seja, para reforço de conteúdos científicos (RAMOS; SILVA, 2014). Nesse modelo, pressupõe-se que a escolha de determinado posicionamento ou interesse do público em relação a questões científicas é devido a um "déficit" cognitivo/cultural (FAPESP, 2005). Uma vez que o indivíduo tome conhecimento das definições e conceitos científicos, por meio de uma comunicação unidirecional (top-down), ele tem um critério confiável e seguro para escolher um posicionamento. No entanto, o modelo do déficit dá pouca atenção a outros tipos de conhecimentos e valores que são relevantes na vida real dos indivíduos, como a confiança no julgamento proveniente de membros da família, amigos ou religiosos (STURGIS; ALLUM, 2004).

Numa situação de sala de aula, podemos exemplificar o uso desse modelo quando o professor usa um documentário em sala de aula e posteriormente realiza uma atividade com os estudantes, em que é pedida a definição de termos ou conceitos científicos presentes no recurso audiovisual. Como nas aulas tradicionais de Ciências, esse tipo de atividade posiciona os estudantes como uma audiência passiva diante das informações científicas veiculadas pelo audiovisual. Embora consideremos importante que os professores desenvolvam atividades dessa natureza, devemos levar em conta que existem modelos de natureza mais participativa, e que levam em conta conhecimentos contextuais relacionados à vida cotidiana dos indivíduos.

Um desses modelos é o contextual e o outro o de participação pública. No modelo contextual, levamos em consideração que as pessoas processam as informações de acordo com modelos sociais e psicológicos que foram construídos historicamente por meio de experiências, contexto cultural e situações pessoais (STURGIS; ALLUM, 2004; SCHEUFELE; LEWENSTEIN, 2005; FAPESP, 2005). Atividades desenvolvidas com o audiovisual em sala de aula, tendo em vista esse modelo, podem contribuir para a descentralização do professor como único produtor de significados no contexto escolar (PEREIRA; ALMEIDA, 2017). Nessa perspectiva, o professor pode usar um DDC como ponto de partida para a discussão de temas científicos controversos, analisando como os estudantes reinterpretam e negociam os conteúdos veiculados pelo audiovisual. A escolha de temas científicos con- 
temporâneos, que são discutidos no cotidiano dos estudantes, pode contribuir para que o professor investigue o papel desempenhado pelos contextos cultural, social e de vivência individual desses estudantes na argumentação e posicionamento dos estudantes em relação às temáticas discutidas.

Muitas são as temáticas científicas atuais circuladas nos diversos gêneros midiáticos e que fazem parte do imaginário social dos estudantes, por exemplo: clonagem, manipulação de células-tronco, transgênicos, os efeitos adversos da telefonia celular, a manipulação do genoma de seres vivos, o uso de produtos químicos, a descoberta do bóson de Higgs, detecção das ondas gravitacionais, descoberta de planetas fora do sistema solar, possibilidade de vida fora da Terra etc.

Já o modelo de participação pública não leva em conta apenas o contexto da descoberta, mas também, os processos de construção da ciência e principalmente como os cidadãos podem tomar decisões nos delineamentos políticos e empresariais dos resultados e possíveis riscos das pesquisas científicas. Essas decisões, no entanto, não devem se basear em argumentos obscurantistas, mas sim, na busca por se informar sobre os assuntos científicos discutidos e de suas implicações para a sociedade, analisando os argumentos apresentados por diferentes interlocutores (SCHEUFELE; LEWENSTEIN, 2005; GALVÃO; REIS; FREIRE, 2011; PRAIA; PÉREZ; VILCHES, 2007). Atividades com DDC em aulas de Ciências, tendo em vista esse modelo, além de levar em conta os aspectos contextuais na produção de significados pelos estudantes, podem contribuir para o desenvolvimento de um espírito crítico que lhes permita não só compreender, mas também avaliar os fatos e os acontecimentos científicos, além de seus riscos e relevância social (FAPESP, 2005, p. 12-9).

Dessa forma, defendemos que a realização de atividades com uso da DC em sala de aula não deve se limitar apenas ao modelo do déficit, mas também levar em consideração os modelos contextualista e o de participação pública. Neste trabalho, apresentamos algumas sugestões de como isso pode ser feito.

Tendo em vista os modelos já discutidos, consideramos importante a aprendizagem de outras leituras de Ciências veiculadas pela mídia no contexto escolar, usando metodologias que valorizem os aspectos da natureza da ciência, em especial, as questões sociocientíficas.

A visão de leitura, na forma que a pensamos, se aproxima da de Ramos e Silva (2014, p. 52):

[...] a noção de leitura se aplica tanto aos textos verbais, quanto às imagens em movimento e sons no vídeo. Quando nos referimos, portanto, à formação de um leitor de Ciências, incluímos a leitura da diversidade de textos nos quais circulam formações discursivas científicas e não científicas, ou referentes científicos. A leitura, tomada como acontecimento no domínio do simbólico, pode ser entendida como leitura de televisão, do cinema, da fotografia, da música. E o simbólico é sempre aberto e é, por isso, ao mesmo tempo, administrado. Umas das instâncias onde se dá essa administração do simbólico é o ensino de Ciências escolar, que nos produz também como sujeitos-leitores de Ciências (RAMOS; SILVA 2014, p. 52). 
No caso particular dos DDC, esses são pouco abordados como objeto de estudo nos cursos de formação de professores, sendo assim, o professor fica desarmado para proceder à escolha desse tipo de produção fílmica, por falta de reflexões que apontem critérios de seleção, uso e elaboração de atividades com esses recursos em sala de aula (BRUZZO, 1998). Ao nos despertar a capacidade de ver questões oportunas que necessitam de atenção, os documentários colocam diante de nós questões sociais e atualidades, problemas recorrentes e soluções possíveis (NICHOLS, 2010). A potencialidade dos documentários em suscitar discussões de natureza científica, histórica e social em sala de aula pode proporcionar um espaço de criação para o professor, além de contribuir para o desenvolvimento do pensamento crítico dos estudantes (BARBOSA; BAZZO, 2013; PEREIRA, 2017).

\section{DoCUMENTÁRIOS DE DIVUlGaÇão CIENTÍFICA: TIPOS E ESTILOS}

Entre as diversas materializações da Divulgação Científica (DC), está o Documentário de Divulgação Científica (DDC). Podemos considerar que o documentário, por seu caráter educativo e pela produção de efeitos de verdade, foi um dos primeiros recursos audiovisuais a entrar em sala de aula. No entanto, apesar dessa parceria ser antiga, notamos que o uso desses recursos nas disciplinas científicas se dá em grande parte para motivação e reforço de conteúdo, ou seja, de acordo com o modelo do déficit.

Descrevemos a seguir os principais tipos e características dos DDC, particularmente os de tradição inglesa e norte-americana, produzidos pelos canais British Broadcasting Corporation (BBC), Public Broadcasting Service (PBS) e History Channel. Consideramos que os DDC produzidos por esses canais possuem uma narrativa que combina explicação e exposição de conteúdos científicos, com o uso de efeitos especiais, entrevistas com cientistas, dramatizações, apresentando um equilíbrio entre a linguagem do rigor científico e a dramaticidade da mídia televisiva (DIJCK, 2006; LEON, 2008).

Consideramos importante a compreensão dos principais tipos e estilos de DDC existentes, no sentido de instrumentalizar os professores com critérios de escolhas e reflexões quando forem usar esses recursos em suas aulas de Ciências. Essas reflexões podem contribuir para a seleção de DDC que se enquadrem aos objetivos das atividades desenvolvidas, tendo em vista os modelos de DC já descritos. Quais os tipos de DDC mais adequados quando pensamos em desenvolver atividades tendo em vista o modelo contextual? E o modelo de participação pública? Que critérios devemos levar em conta ao selecionar um DDC tendo em vista esses modelos? Que tipos de questões podemos discutir com os nossos alunos?

A palavra inglesa documentary foi usada pela primeira vez por John Grierson (18981972), em 1926, em referência ao filme Moana de Robert Flaherty (1884-1951) (JESUS, 2008; LEON, 2007). Grierson foi um dos responsáveis pelo início do movimento do documentário britânico, e sua preocupação inicial era o despreparo do cidadão britânico para lidar com questões da sua atualidade. De acordo com ele, o documentário funciona para o fortalecimento da educação formal tradicional que não estava dando conta da realidade mais concreta do mundo (LEON, 2007). 
Os principais tipos ou estilos de documentários existentes atualmente, de acordo com Nichols (2005, p. 47-49), são:

- Discurso direto. Da tradição de Grierson, estabeleceu-se como uma forma acabada de documentário, por isso também classificado como documentário clássico. Sua principal característica é a narração fora de campo, quase sempre arrogante e em muitos casos a narração domina os elementos visuais, embora possa ser poética e evocativa;

- Cinema direto. Com promessas de "efeitos de verdade" graças à objetividade, ao imediatismo e à impressão de capturar fielmente acontecimentos ocorridos na vida cotidiana das pessoas. O estilo busca tornar-se "transparente" captando as pessoas em ação e deixando que o espectador tire conclusões sobre elas sem a ajuda de qualquer comentário, implícito ou explícito.

- Filme de entrevista. Incorpora o chamado discurso direto, no qual personagens ou o narrador falam diretamente ao espectador, geralmente na forma de entrevistas. Esses filmes forneceram o modelo para o documentário contemporâneo.

- Documentário autorreflexivo. Esse tipo de documentário mistura passagens observacionais com entrevistas, a voz sobreposta do diretor com intertítulos, deixando claro o que sempre esteve implícito: o documentário é uma forma de representação, e nunca uma janela para a realidade. O cineasta sempre é testemunha participante e ativo fabricante de significados, muito mais um produtor do que um repórter neutro ou onisciente da verdadeira realidade das coisas.

Além destes, um subgênero de DDC que se tornou muito popular nos últimos anos é o docudrama (REID, 2011). O docudrama emprega recursos cinematográficos típicos do drama ficcional associados a técnicas tipicamente usadas em documentários, por exemplo, entrevistas de cientistas renomados. Geralmente, atores interpretam cientistas, e dramatizam as dificuldades, pessoais e científicas, enfrentadas por estes no desenvolvimento de suas teorias. Neste trabalho, sugerimos possibilidades de uso em sala de aula de dois docudramas: A equação de vida e morte de Einstein (A EQUAÇÃO, 2005) e A grande ideia de Einstein (A GRANDE IDEIA, 2005) produzidos conjuntamente pela BBC e PBS NOVA, em 2005, em comemoração ao Ano Mundial de Física.

De modo geral, as características que atribuímos a um documentário no sentido de classificá-lo como sendo de divulgação científica, de acordo com Leon (2007, p. 210), são: 1. Eles focam assuntos que são resultados de pesquisas, fatos ou conhecimentos relacionados diretamente a alguma disciplina científica ou em algum tipo de argumentação ancorada em conhecimento científico, seja teórico ou aplicado, e 2. Eles mostram explicitamente (em imagens, na narração ou nos créditos) que têm colaboração e suporte de cientistas ou instituições, que participam como fontes de informação ou assessorando no conteúdo exposto.

A maioria dos DDC atuais segue os modelos de discurso direto ou filme de entrevista. O discurso direto consiste em um narrador ou uma voz fora de campo, invisível ao espectador, que explica um conceito científico ou uma teoria (DIJCK, 2006). Essa narração se dá com a ajuda de estratégias retóricas, por meio do uso de analogias e metáforas, que 
contribuem para a compreensão dos assuntos narrados. Às vezes, o narrador é visível ao espectador e possui sólido conhecimento científico na área dos assuntos discutidos. Como apontado por Dijck (2006, p. 8): "Os espectadores são mais propensos a confiar em afirmações feitas pelas próprias pessoas que pesquisaram ou pesquisam o assunto que está sendo tratado no documentário e cuja autoridade é institucionalmente legitimada". Quando, além de narrarem, os apresentadores realizam entrevistas temos os filmes de entrevista. Para produzir efeitos de realidade, são mostradas imagens, analogias, metáforas, depoimentos, que têm como objetivo promover a compreensão do público sobre os assuntos científicos que estão sendo discutidos. Ao explicar o significado de salto quântico, no documentário O átomo (O ÁTOMO, 2007), por exemplo, o físico Jim Al-Khalili utiliza um edifício onde os andares representam as órbitas possíveis para o elétron no átomo de hidrogênio. No mesmo documentário ele explica o princípio da exclusão de Pauli, utilizando o fato de que os andares só podem ser ocupados por um número limitado de elétrons.

Associado às estratégias já citadas, os produtores de DDC ainda utilizam efeitos especiais originados, principalmente, pelo desenvolvimento da computação gráfica nos últimos anos. No documentário O universo elegante (O UNIVERSO, 2003), o físico norte-americano Brian Greene utiliza animações digitais com o objetivo de visualização dos conceitos explicados no documentário. Ele usa a vibração das cordas de um violoncelo para relacionar com a teoria das cordas, uma xícara de café e uma rosca para ilustrar a importância das formas e o corte de fatias de pão para exemplificar a existência de universos paralelos. Durante as explicações, as cenas são entrecortadas com efeitos visuais acompanhando a narração do apresentador, cujos efeitos intentam aproximar os conceitos abstratos da teoria das cordas e o telespectador (DIJCK, 2006).

Esses estilos de DDC, apesar de serem considerados excelentes para atrair a atenção dos espectadores, para informar sobre conhecimentos científicos, podem contribuir para direcionar o espectador a concordar com determinados pontos de vista ideológicos e políticos dos usos e resultados da pesquisa científica (BUCCHI, 1998). Nesse sentido, acreditamos que o professor é o principal ator que pode contribuir no desenvolvimento de discussões em sala de aula, possibilitando o surgimento da argumentação entre os seus alunos, com o objetivo de produzir outras leituras das narrativas audiovisuais.

No documentário norte-americano Uma verdade inconveniente (UMA VERDADE, 2006), por exemplo, o ex-vice presidente norte-americano Al Gore utiliza slides, gráficos, vídeos de catástrofes e entrevistas de cientistas respeitados com o objetivo de sensibilizar o espectador sobre as consequências do aquecimento global e sua relação com a produção de $\mathrm{CO}_{2}$ na atmosfera terrestre, principalmente após a Revolução Industrial (RAMOS; SILVA, 2014). No entanto, um ano depois, o Canal 4 Britânico transmitiu o documentário A grande farsa do aquecimento global (A GRANDE FARSA, 2007) utilizando os mesmos recursos retóricos usados por $\mathrm{Al}$ Gore, porém, com o objetivo de desacreditar a responsabilidade humana no fenômeno do aquecimento global. Esses dois documentários podem contribuir para a discussão de questões sociocientíficas em aulas de Biologia do Ensino Médio, com a mediação e preparação prévia do professor, ao solicitar aos estudantes que desenvolvam argumentações ao defender suas opiniões (PEREIRA, 2017). 
É importante salientar que o DDC é apenas um, entre muitos recursos existentes, que podem ser usados em sala de aula com o intuito de desenvolver atividades diferenciadas. $\mathrm{O}$ uso de DDC, além das propostas de visualização e reforço de conteúdos, exige uma preparação prévia do professor. Essa preparação pode envolver atividades nos cursos de formação inicial ou continuada, relacionadas à leitura das representações de ciência transmitidas pela mídia. De acordo com Reid e Norris (2016, p. 148):

\footnotetext{
O estudo destas representações trará grandes contribuições para o ensino de Ciências, pois a compreensão, avaliação e a crítica fundamentada sobre as representações da ciência na mídia não requer somente conhecimentos sobre a mídia, mas também, sobre a natureza da ciência e seus conteúdos (REID; NORRIS, 2016, p. 148).
}

Assim como o formador de professor e o professor da educação básica, a atividade realizada e preparada por esses é que vai determinar a natureza do engajamento entre seus alunos. Como apontado por Almeida (2012, p. 38):

Qualquer recurso é apenas um recurso, com determinados potenciais. Seu uso depende de como é organizada a aula pelos professores formadores de professores ou pelos professores do ensino básico. Estes, além de direcionarem a natureza das atividades proposta com o uso dos recursos disponíveis, são os mediadores da circulação dos discursos na sala de aula (ALMEIDA, 2012, p. 38).

De modo geral, a ciência ensinada em sala de aula pode cumprir com um papel mais abrangente do que apenas a aprendizagem de habilidades relacionadas à operacionalização de fórmulas matemáticas. Ela pode contribuir também para a formação de um cidadão leitor de Ciências em suas diversas materializações, como revistas de divulgação científica, filmes de ficção e documentários.

\section{Documentários de divUlgaÇão Científica: POSSIBILIDAdes de USO EM SALA DE AULA}

Neste item, analisamos cinco DDC, categorizando-os de acordo com os tipos e estilos propostos por Nichols (2005). Além disso, conforme essa categorização, sugerimos algumas formas de utilização desses DDC em sala de aula, tendo em vista os modelos de divulgação da ciência já descritos. Salientamos que essas sugestões objetivam ir além dos usos que os professores fazem desses recursos em sala de aula e já identificados por pesquisadores na área de ensino de Ciências, ou seja, para motivar, ilustrar e complementar conteúdos.

As sugestões e propostas de utilização descritas a seguir consideram que o ator principal em ressignificar e refletir sobre a viabilidade ou não de implementá-las em sua realidade escolar é o professor. Essas atividades têm como objetivo a transformação das práticas educativas do professor em sala de aula. Essas, no entanto, não são condicionadas a um programa

Comunicações | Piracicaba | v. 26 | n. 1 | p. 241-267| jan.-abr. 2019 
de diretrizes e recomendações vazias que têm como foco dizer ao professor o quê, quando e como trabalhar com seus alunos. As recomendações vazias são aquelas em que o professor recebe informações a respeito dos resultados de intervenções realizadas em sala de aula por "especialistas" sem, no entanto, essas recomendações serem acompanhadas do apoio teórico/ metodológico que justificou os procedimentos recomendados (ALMEIDA, 2006).

\section{DDC1: A EQUAÇÃo dE VIDA E MORTE DE EINSTEIN}

A equação de vida e morte de Einstein (A EQUAÇÃO, 2005) foi um docudrama produzido em 2005, pelo Canal 2 da BBC em comemoração aos 100 anos da Teoria da Relatividade Especial. O documentário se inicia encenando o encontro realizado entre os cientistas Albert Einstein (1879-1955) e Leo Szilard (1898-1964), em 1939. Nesse encontro, Szilard convence Einstein a escrever sua famosa carta ao presidente dos Estados Unidos, Franklin Delano Roosevelt (1882-1945), alertando-o sobre a possibilidade dos alemães construírem uma bomba atômica. Por se tratar de um docudrama, há a preocupação dos produtores em deixar claro para o espectador que, apesar de se tratar de uma ficção, ela é ancorada em eventos reais (REID, 2011). Para isso, logo no início do documentário, aparece uma nota na tela dizendo: "Os elementos dramatizados neste filme são baseados em eventos reais da vida de Albert Einstein" e "Os diálogos aqui produzidos são baseados em relatos de testemunhas oculares e registros históricos". Como apontado por Dijck (2006), esses elementos textuais têm como objetivo conferir credibilidade e efeitos de "verdade" à narrativa audiovisual. Estratégia importante, principalmente por se tratar de um docudrama.

Paralelo às cenas de ficção, o narrador, fora de campo, constrói uma narrativa histórica apresentando as principais dificuldades encontradas pelos físicos da primeira metade do século XX para produzir a fissão nuclear do núcleo atômico. São mostrados vídeos animados simulando a colisão de partículas atômicas com o núcleo atômico e a consequente reação em cadeia. Entre uma cena e outra, há entrevistas de cientistas e historiadores da ciência, confirmando, por meio de relatos históricos, a importância de Szilard, Einstein e de sua equação para o desenvolvimento da física nuclear e da ciência no século XX. Além disso, são exibidos vídeos antigos contextualizando a ascensão do nazismo na Alemanha, nessa mesma época.

Esse documentário tem potencialidades de utilização para trabalharmos com os três modelos de divulgação já descritos. Numa perspectiva de uso do modelo do déficit, poderíamos pedir para os alunos usarem a equação de Einstein para calcular a quantidade de energia liberada nas principais reações de fissão e fusão nuclear, e comparar essa energia com outros tipos de energia do cotidiano deles, por exemplo, a energia elétrica. Para isso, poderíamos dar uma aula introdutória sobre esses assuntos antes de passar o documentário. Durante a transmissão do documentário, poderíamos pedir para os alunos anotarem os termos científicos que eles não conhecem o significado para posterior discussão. Nesse sentido, os tipos de atividades solicitadas têm como objetivo reforçar os conteúdos da aula introdutória e motivar os estudantes a pesquisarem mais a respeito dos assuntos discutidos. 
Já numa perspectiva de modelo contextual, podemos usar elementos da Natureza da Ciência ( $\mathrm{NdC}$ ) presentes no documentário para que os estudantes pesquisem e discutam a veracidade das informações históricas transmitidas. Para isso, as atividades desenvolvidas poderiam ser realizadas numa perspectiva multidisciplinar com o professor de História. Por exemplo, numa cena do documentário Einstein aconselha Szilard para não se envolver em questões militares, pois "A ciência deve se manter a mais neutra possível". Poderíamos questionar os estudantes se Einstein realmente disse essa frase, ou se pensava dessa forma, após uma pesquisa efetuada em outros tipos de mídias. Podemos questioná-los se essa postura seria correta, ou seja, se eles concordam que a ciência deve se manter neutra atualmente.

Durante o documentário é dito que a construção da bomba atômica foi fundamental para os Estados Unidos vencerem a guerra e a Alemanha nazista. Poderíamos pedir para os alunos pesquisarem a veracidade dessas informações, e outras correlacionadas, comparando com as do documentário. Consideramos esses tipos de atividades fundamentais quando objetivamos ensinar os estudantes a realizarem a leitura das representações de ciência e de cientista transmitidas pelos recursos audiovisuais (REID; NORRIS, 2016; RAMOS; SILVA, 2014).

Para produzirmos significados sobre a leitura de Ciências pela mídia, é necessário que compreendamos a ciência não apenas como produto, mas principalmente como processo e, para isso, é necessário o conhecimento sobre a NdC (DUSCHL, 1990). A aprendizagem da $\mathrm{NdC}$ é de extrema importância quando consideramos que um dos principais objetivos da educação em Ciências é promover a alfabetização científica dos cidadãos (DHINGRA, 2003; PRAIA; PÉREZ; VILCHES, 2007; BLOOM; BINNS; KOEHLER, 2015). Usamos o termo alfabetização científica neste projeto em relação aos modelos de divulgação da ciência já apresentados. No contexto de nosso trabalho, a alfabetização científica pela mídia, não envolve apenas a capacidade de conhecer conceitos e teorias científicas, como preconizado pelo modelo do déficit, mas também correlacionar o conhecimento científico com o conhecimento a respeito da mídia, no intuito de saber escolher, entender, avaliar e responder as representações de ciência na mídia (REID; NORRIS, 2016). Se continuarmos a não valorizar, em sala de aula, assuntos relacionados à $\mathrm{NdC}$, os estudantes continuarão a aprender Ciências de uma maneira descontextualizada, não permitindo a compreensão de forma aprofundada do conhecimento científico produzido e usar esse conhecimento para tomar decisões pessoais e sociais informadas (McCOMAS, 2000).

O documentário A equação de vida e morte de Einstein pode possibilitar, ainda, o desenvolvimento de atividades tendo como foco o modelo de participação pública, pois se trata, em última análise, de uma narrativa histórico-científica sobre os perigos ocasionados pela energia nuclear. Após assistirem o documentário, os estudantes formariam dois grupos: aqueles que conferem responsabilidade a Einstein pela construção da bomba atômica e aqueles que acreditam que Einstein não teve responsabilidade sobre a construção da mesma. Os estudantes seriam convidados a defenderem seus pontos de vista ancorados principalmente nas informações transmitidas pelo documentário. De outro modo, poderíamos formar dois grupos: aqueles que concordam que Einstein tenha escrito a carta para o presidente Roosevelt e os 
que não concordam. Ao fim da discussão, cada grupo de estudante poderia redigir uma carta, simulando a época em questão, que seria endereçada a um suposto presidente. Uma delas, feita pelo grupo que considerou essencial Einstein ter escrito a carta, justificando a necessidade da construção da bomba. Outra, com elementos que justificassem a não necessidade de construção da bomba. Nessas cartas, poderiam conter, por exemplo, cálculos simples usando a equação de Einstein da energia liberada em reações nucleares.

Nos últimos minutos do documentário, é mostrado outro aspecto da equação de Einstein, mais voltado à explicação das grandes questões da Física e da Astronomia. Por exemplo, e explicação da origem da energia do sol, através da fusão, ou a utilização da energia nuclear para fins benéficos, como os reatores nucleares. Os estudantes poderiam, enfim, "julgar" a equação de Einstein: ela é da "morte" ou da "vida". Qual a responsabilidade do cientista ou da ciência, ao usar essa equação?

\section{DDC2: ESTAMOS SOZINHOS NO UNIVERSO?}

Estamos sozinhos no universo (ESTAMOS SOZINHOS, 2008) foi um DDC produzido pelo canal britânico BBC Two, em 2008. Ele trata da possibilidade de existência de vida fora da terra. Pode ser considerado, de acordo com a classificação de Nichols, como filme de entrevistas. É narrado por uma voz over fora de campo durante todo o tempo e repleto de entrevistas com vários cientistas que pesquisam a possibilidade de vida fora da terra. $\mathrm{O}$ documentário faz uma viagem aos principais laboratórios do mundo que realizam pesquisa nessa área e um pequeno histórico de como se desenvolveu a pesquisa de vida extraterrestre no século XX. Relata a descoberta de planetas fora do nosso sistema solar nas últimas décadas e o estudo realizado para determinar a sua composição química e física. Apresenta também uma entrevista com o cientista norte-americano Frank Drake (1930-) responsável pela equação que leva seu nome e um dos fundadores, com Carl Sagan (1934-1996), do SETI (Search for Extraterrestrial Intelligence), instituição que tem por objetivo a pesquisa na busca de vida fora da terra.

Nesse documentário, observamos uma narrativa favorável à continuação das pesquisas relacionadas à existência de vida fora da terra. Nesse sentido, o discurso produzido pelos cientistas entrevistados, é o de confirmação de uma hipótese: a provável existência de vida fora da Terra, pois, se não houvesse essa possibilidade, para que continuar a se investir em pesquisas nessa direção. Logo no início do documentário, um dos cientistas entrevistados, o astrônomo Seth Shostak comenta:

Existem algumas centenas de bilhões de estrelas apenas em nossa galáxia, e pelo menos metade delas provavelmente tem planetas. Isso significa $100 \mathrm{bi}$ lhões de sistemas planetários. Quantos planetas em cada sistema? Digamos cinco. Isso significa meio trilhão, 500 bilhões de planetas! Não se esqueça, que existem 100 bilhões de outras galáxias! Imaginar que a Terra é o único lugar onde coisas interessantes acontecem é um ponto de vista muito audacioso! (ESTAMOS SOZINHOS, 2008). 
Por sua vez, o documentário relata que todas as tentativas em encontrar vida fora da Terra, realizadas nos últimos 50 anos, falharam. Um ponto a ser destacado é que o documentário apresenta como a Astronomia, ao se apropriar de conhecimentos produzidos pela Física nas últimas décadas, ampliou seu campo de pesquisas, contribuindo para ampliar a nossa visão do universo. Uma dessas pesquisas é a procura de exoplanetas, ou seja, planetas orbitando estrelas fora do nosso sistema solar. Além disso, ele mostra, por meio de visitas a observatórios e entrevistas com astrofísicos, o cotidiano de trabalho desses pesquisadores, que no documentário recebem o nome de "caçadores de planetas".

Uma das possibilidades de uso desse documentário em sala de aula, que consideramos relevante quando pensamos no modelo de participação pública da ciência, é por meio da discussão de controvérsias científicas. Estudos na área de ensino de Ciências têm apontado para a importância de realizarmos atividades em sala de aula enfatizando a discussão de controvérsias (NARASIMHAN, 2001; KIPNIS, 2001; NASCIMENTO; ALVETTI, 2006; RAMOS; SILVA, 2007; RAMOS, 2010; SILVA, VELASCO, ZANOTELLO, 2016).

Um dos argumentos científicos muito usados quando pensamos em iniciar um debate sobre a existência de vida fora da terra envolve a questão da dimensão do universo. Como apontado por Horvath (2008, p. 194):

Sabemos que existem no universo visível aproximadamente 2 bilhões de ga-
láxias. Ao supor que todas as galáxias são similares à nossa, admitimos que
cada uma delas contém 100 bilhões de estrelas, a maioria delas do tipo solar
ou menos massivas. Se cada estrela abrigasse pelos menos um planeta como o
nosso, poderia haver $10^{20}$ "Terras", ou planetas rochosos com possibilidades de
abrigar algum tipo de vida. Estes números são muito grosseiros, mas servem
para abordar a partir de uma perspectiva científica o problema de existência de
vida extraterrestre (ET) (HORVATH, 2008, p. 194).

Temáticas dessa natureza, envolvendo controvérsias científicas, nas quais o caráter da não neutralidade da ciência e dos cientistas é posta em xeque, podem dar grandes contribuições para discussões em sala de aula. De acordo com Ramos e Silva (2007, p. 6):

De qualquer modo, é importante destacar que há um "algo mais" no envolvimento dos especialistas (técnicos e cientistas) em questões controversas que vai além da oferta de um "conhecimento verdadeiro" que possa confirmar ou descartar uma hipótese ou trazer um final às questões. E, nesse sentido, alguns estudos de caso provenientes dos estudos de controvérsia podem ser importantes, se conduzidos à sala de aula: demonstrando o quão efêmeras, mutáveis, incompletas podem ser as certezas dos conhecimentos científicos (como todas as outras certezas) e que, de qualquer forma, influenciarão de maneira significativa o modo como julgaremos todos esses conhecimentos na hora de definir nossas ações perante a vida (RAMOS; SILVA, 2007, p. 6).

Numa perspectiva de aula em que gostaríamos de promover o debate entre os alunos, característica essencial da participação pública e da própria construção dos conhecimentos 
científicos, o assunto escolhido tem alto potencial para o desenvolvimento da argumentação entre os alunos. Poderíamos considerar argumentos científicos, tanto favoráveis quanto contra a possibilidade de vida extraterrestre retirados do próprio documentário ou pela leitura de textos complementares. Um texto que poderia ser usado para acirrar o debate é o de Barcelos e Quillfeldt, publicado na revista Scientific American online, "Onde estão todos os outros?"

Um dos argumentos a favor da existência de vida fora da Terra poderia ser o dado por Horvath na citação mencionada. Ou seja, muitas galáxias, muitas estrelas e, por conseguinte, muitos planetas que têm as características de serem "habitáveis". Ou, caso contrário, se o posicionamento é contra a existência de vida fora da terra, poderíamos usar o argumento do físico Enrico Fermi (1901-1954) na década de 50, do século XX. O tempo que uma civilização leva para se desenvolver e viajar pela galáxia é muito menor que o tempo disponível para a evolução dos planetas e as estrelas das galáxias. Assim, se houve condições da terra ter desenvolvido vida há mais de três bilhões de anos, e isso é similar ao que aconteceu em muitos outros planetas e ocorre ainda hoje, deveríamos ter recebido a visita de ETs há muito tempo. Como isso não é observado, onde estão eles? (HORVATH, 2008).

De qualquer forma, esse é um assunto que pode ser trabalhado sob o viés de controvérsias científicas em sala de aula. Como apontado por Ramos e Silva (2007, p. 3):

$\mathrm{O}$ acesso às argumentações produzidas por cientistas em situações de divergência e conflitos no processo de produção de conhecimentos pode significar uma importante contribuição desses estudos para o ensino de Ciências (RAMOS; SILVA, 2007, p. 3).

A avaliação da atividade pode ser realizada por meio da participação dos grupos na defesa de suas opiniões, e na análise dos tipos de argumentação usada pelos estudantes: religiosa, filosófica, científica etc. Poderíamos pedir para que os estudantes escrevam uma carta endereçada a outro estudante que possui uma postura diferente da sua, na tentativa de mudar sua opinião sobre o assunto discutido. Nessa carta, poderíamos avaliar o tipo de argumentação usada pelos estudantes e se eles empregam exemplos retirados do documentário para defender sua postura. Isso teria como objetivo, além da avaliação dos estudantes, investigarmos qual o papel do documentário na produção de significados pelos estudantes.

\section{DDC3: COMO A CIÊNCIA MUDOU NOSSO MUNDO?}

O documentário Como a Ciência mudou nosso mundo? (COMO A CIÊNCIA, 2010) foi produzido, em 2010, pelo canal britânico BBC One. Nele, o Professor Robert Winston, cientista e médico de formação, apresenta as dez maiores descobertas científicas dos últimos 50 anos do século XX e os seus respectivos impactos na sociedade. De acordo com ele, algumas dessas descobertas foram: Microchip, Internet, Projeto Genoma Humano, Laser, Teoria do Big Bang e Ressonância Magnética.

Podemos classificá-lo como filme de entrevistas, diferenciando-se do de discurso direto pela presença do narrador, neste caso o próprio Winston, que fala diretamente 
ao espectador. Os entrevistados são cientistas, engenheiros, médicos, astrônomos que participaram ou participam no desenvolvimento das descobertas narradas, e pessoas que foram beneficiadas por essas descobertas. Quando o apresentador narra a descoberta e o uso da ressonância magnética, ele entrevista um pesquisador da área e uma mulher que é beneficiada pela técnica no tratamento de um tumor cerebral. Um ponto importante desse documentário é que ele abre espaço para a participação do espectador. Quando o documentário foi ao ar em 2010, o site da BBC One deixou um espaço aberto para que o espectador pudesse votar qual, em sua opinião, foi a descoberta mais importante narrada no documentário. Após um período de votação, o site abriu um espaço para discussão a respeito do resultado da votação. Atualmente, o resultado da votação se encontra no Wikipédia sobre o documentário. ${ }^{1}$

Consideramos que esse documentário pode ser trabalhado usando um viés contextualista e de participação pública. Podemos pedir aos estudantes que votem na descoberta que eles avaliam mais importante, justificando o seu voto com informações retiradas do documentário, ou por uma pesquisa realizada em outras mídias. Podemos comparar os resultados da votação efetuada em sala de aula com a votação encontrada no site Wikipédia. Podemos ainda realizar uma votação pedindo para os estudantes escolherem alguma descoberta que eles consideram importante, mas que não foi analisada no documentário.

Um ponto que consideramos problemático nesse documentário é que ele traz uma visão ingênua e unidirecional de ciência, ou seja, maior desenvolvimento científico gera mais tecnologia, que promove mais riqueza e, portanto, um aumento do bem-estar social. Poderíamos pedir aos estudantes para pesquisarem o "outro lado" de cada descoberta. Numa parte do documentário, Winston fala dos benefícios do laser na medicina e em sua utilização na fusão de núcleos de hidrogênio, com esperanças de, num futuro próximo, a humanidade conseguir energia limpa. Os estudantes podem pesquisar outras utilizações do laser, por exemplo, em tecnologia bélica. Numa relação entre tecnologia e sociedade, podemos nos questionar sobre quem são as pessoas que têm acesso aos produtos da ciência. Será que todos os cidadãos brasileiros têm acesso a um aparelho de ressonância magnética? Assim, o documentário pode promover o fio condutor para discussões mais abrangentes sobre os impactos das descobertas científicas modernas na vida dos cidadãos, sejam positivas ou negativas.

O documentário narra descobertas científicas que impactaram as relações entre ciência, tecnologia e sociedade ao longo da segunda metade do século XX. Diversas aplicações da ciência e tecnologia são apresentadas. Poderíamos pedir para os estudantes entrevistarem pessoas da comunidade local que foram beneficiadas por algumas dessas descobertas. Essas entrevistas podem ter um caráter informativo, ou seja, os estudantes podem contribuir para popularizar essas descobertas em sua comunidade.

https://en.wikipedia.org/wiki/How_Science_Changed_Our_World 


\section{DDC 4: A CAVERNA DOS SONHOS ESQUECIDOS}

A caverna dos sonhos esquecidos (A CAVERNA, 2010) foi um documentário produzido, em 2010, pelo canal norte-americano History. Ele possui elementos de filme de entrevistas e documentário autorreflexivo. Devido às dificuldades técnicas de se fazer as filmagens dentro da caverna retratada no documentário, o próprio Werner Herzog (diretor do documentário), filma, narra e realiza entrevistas.

A classificação de documentário autorreflexivo se dá pelo fato de que as questões elaboradas por Herzog não se limitam àquelas relacionadas à transmissão e confirmação de um discurso científico. Consideramos que essa característica distingue esse documentário de grande parte dos DDC produzidos atualmente. Há um espaço considerável para a imaginação e criatividade que proporcionam e instrumentalizam o espectador para produzir um vasto campo de reflexões (PEREIRA, 2017). Por exemplo, quando Herzog entrevista o cientista Jean-Michel Geneste, este, além de explicar para o espectador as técnicas de pintura usadas pelo homem do Paleolítico, também especula sobre como era feita a caça por esses homens. Ao entrevistar o antropólogo Julien Monney, este menciona que já tinha trabalhado como artista de circo. Ao estudar uma pintura encontrada na caverna chamada Painel dos Leões, Monney menciona que teve de abandonar momentaneamente suas visitas à caverna. Herzog pergunta se isso tem relação com o fato de ele ter trabalhado no circo. Esse tipo de questão sugere a coexistência de dois tipos de discursos: um, de uma posição de artista de circo, imbuído de fantasia, imaginação e obsessão pelas descobertas da caverna, e outro, da posição de cientista (KLINGER, 2012).

Como apontado por Leão (2015), o documentário de Herzog não segue um modelo clássico de documentário de divulgação científica, por vários fatores, entre eles, pelo fato de que as entrevistas realizadas não valorizam apenas o conteúdo científico:

As escolhas do diretor deixam claro que o recorte de cada relato vai além da explicação técnica sobre o assunto: busca-se o olhar íntimo sobre a história e a singularidade de cada um, e como esse traço pode contribuir para o conjunto do que está sendo pesquisado (LEÃO, 2015, p. 87).

De fato, a narração, as entrevistas, os diálogos, o enquadramento das imagens, a trilha sonora etc., evocam discussões e debates que vão além das explicações dos conceitos científicos subjacentes às pinturas rupestres descobertas. É claro que sem a ciência saberíamos pouco sobre as pinturas, no entanto, com a imaginação e a criatividade, podemos saber muito mais além do que seu tempo de existência, proporcionado pela técnica do Carbono 14.

Esse documentário pode contribuir para trazer para a sala de aula uma crítica ao modelo de explicação clássica da ciência que, nas palavras de Morin (2010, p. 30):

Tende a reduzir o conhecível ao manipulável. Hoje, há que insistir fortemente na utilidade de um conhecimento que possa servir à reflexão, meditação, discussão, incorporação por todos, cada um no seu saber, na sua experiência, na sua vida (MORIN, 2010, p. 30). 
O documentário começa narrando a descoberta de uma caverna encontrada no sul da França, em dezembro de 1994, por três espeleologistas: Jean-Marie Chauvet, Éliette Brunel e Christian Hillaire. Hoje, essa caverna é conhecida como caverna de Chauvet em homenagem ao seu primeiro descobridor. Dentro da caverna, os pesquisadores encontraram uma série de pinturas nas paredes, aproximadamente 400 delas no total. Um dos fatores que tornaram a sua descoberta importante é a idade dessas pinturas, estimada em aproximadamente 32 mil anos. Com efeito, segundo Cabral (2011, p. 312):

\begin{abstract}
Enquanto a estimativa da idade de suas magníficas pinturas, feitas por Jean Clottes pouco depois de sua descoberta, com base nos primeiros dados estilísticos obtidos, as colocavam no Solutrense (21.000 a 18.000 antes do presente), a datação direta pelo radiocarbono de um de seus mais espetaculares desenhos - o combate dos rinocerontes - dava como resultado valores de 31.000 antes do presente. A diferença era da ordem de grandeza de 10.000 anos! (CABRAL, 2011, p. 312).
\end{abstract}

O uso da técnica de datação por Carbono 14 ocasionou uma mudança significativa na metodologia de trabalho da Arqueologia e, no caso das pinturas encontradas na caverna de Chauvet, surpreendeu os pesquisadores.

Tendo em vista a perspectiva dos modelos do déficit e contextual, poderíamos pedir para os estudantes identificarem conceitos de Ciências citados no documentário. Ainda em relação ao modelo do déficit, podemos realizar cálculos simples, envolvendo a técnica de datação por Carbono 14, para determinar a idade de algumas das pinturas encontradas na caverna e mostradas no documentário. Esses resultados poderiam ser discutidos em relação às idades de pinturas encontradas em outras cavernas, por exemplo, a caverna de Lascaux (França) e Altamira (Espanha). Essas discussões podem ser feitas numa perspectiva multidisciplinar, tendo a participação dos professores de Artes, História e Química. Algumas questões que poderiam ser trabalhadas são: Como os cientistas sabem a idade das pinturas encontradas na caverna de Chauvet? Como a ciência contribuiu para determinar essas datas? De acordo com o documentário, por que a idade calculada surpreendeu os pesquisadores? Ou ainda, em parceria com o professor de biologia, poderíamos identificar quais animais retratados nessas pinturas já estão extintos atualmente.

Por fim, enfatizamos a necessidade da problematização do professor no sentido de apresentar para os alunos a relação existente entre a Ciência e a Arte, configurada neste documentário por meio da importância da datação por Carbono 14, ao contribuir para uma revolução científica ocorrida na Arqueologia. De acordo com o método arqueológico, a idade das pinturas deveria estar entre 21.000 a 18.000 antes do presente. No entanto, a partir da datação por Carbono 14, essa se fixou em pelo menos 32.000 anos atrás. Quase o dobro previsto pela Arqueologia! 


\section{DDC5: A GRANDE IDEIA DE EINSTEIN}

A Grande Ideia de Einstein (A GRANDE IDEIA, 2005) foi um docudrama produzido e transmitido, em 2005, pelos canais BBC 4 e PBS NOVA e pelo canal brasileiro Futura em 2010. O documentário narra a história dos desenvolvimentos científicos que levaram à famosa equação de Albert Einstein (1879-1955): . A narração é feita fora de campo, característica principal dos documentários ditos de discurso direto, e começa apresentando Einstein como uma pessoa "jovem, dinâmica e atraente". Em seguida, o narrador faz um resumo dos assuntos que serão tratados ao longo do documentário. Em cada capítulo é encenada a história do desenvolvimento de cada termo da equação de Einstein. Cada período histórico representado é dramatizado por um ator ou atriz que interpreta o cientista responsável pelo desenvolvimento da teoria que deu origem a cada termo dessa equação.

O primeiro capítulo se inicia, em 1812, retratando a vida de Michael Faraday (17911867) e como seu "desejo" por conhecimento e "paixão" pela ciência o levaram a desenvolver o conceito de linhas de força elétrica e magnética. Em seguida, é apresentado o período de 1771, quando Antoine Lavoisier (1743-1794) realiza o grande experimento que o leva a chegar ao teorema da conservação da massa. Paralelamente aos feitos científicos de Lavoisier, o documentário faz uma contextualização histórica do período ao qual o cientista viveu, narrando os principais acontecimentos daquela época, particularmente da Revolução Francesa. O documentário exibe ainda, passagens da vida de James Clerk Maxwell (18311879), Émilie du Châtelet (1706-1749) e Lise Meitner (1878-1968).

A primeira atividade que podemos realizar com esse documentário é a criação de uma linha do tempo com os principais cientistas envolvidos no desenvolvimento dos termos da equação de Einstein. Os alunos podem se organizar em grupos, sendo que cada grupo ficará responsável por anotar informações contidas no documentário sobre os conceitos de energia, massa, luz e velocidade (velocidade da luz ao quadrado). Cada termo deve conter os principais cientistas responsáveis pelo seu desenvolvimento, com informações, por exemplo, nacionalidade, momento histórico que viveu, experiência feita e os desafios científicos e pessoais enfrentados. Após essa atividade inicial, os estudantes podem construir uma linha do tempo de 1700 até 1950 e, em seguida, uma discussão com a mediação do professor a respeito das informações contidas nessa linha do tempo e sua relação com a equação de Einstein. Esse tipo de atividade se aproxima do modelo contextualista pois, ao construírem essa linha do tempo, é necessário que os estudantes façam uma pesquisa histórica que vai além da simples aprendizagem de conteúdos puramente científicos.

Outra atividade possível é a exploração do significado de cada letra na equação de Einstein. Para isso, podemos formar grupos que ficarão responsáveis por pesquisar o significado de cada letra: $E, m, c$ e o porquê do $c^{2}$. Quando foi realizado o lançamento desse documentário, em 2005, o canal de televisão americano PBS disponibilizou um Guia do Professor com diversas atividades sobre o documentário. Os autores desse trabalho fizeram uma tradução livre desse Guia e efetuaram algumas das atividades descritas com estudantes 
do Ensino Médio em escolas públicas do município de Piracicaba. ${ }^{2}$ Essas atividades foram realizadas como parte das ações previstas no subprojeto de Física do Programa Institucional de Bolsa de Iniciação à Docência (PIBID) do Instituto Federal de Educação, Ciência e Tecnologia (IFSP) de Piracicaba. Esse Guia traz atividades que se aproximam ao modelo do déficit e contextual já descritos. Existem atividades de cunho experimental, por exemplo, uma atividade com o objetivo de investigar o porquê de a velocidade ser ao quadrado na fórmula da energia cinética, por meio da queda de objetos em uma caixa de areia fina. Ou atividades de cunho teórico, ao pedir que os estudantes calculem e façam um comparativo nas energias envolvidas em viagens espaciais.

\section{CONSIDERAÇões FINAIS}

Neste trabalho, sugerimos algumas formas de se trabalhar com Documentários de Divulgação Científica (DDC) no Ensino Médio (EM) tendo em vista os seguintes modelos de Divulgação da Ciência (DC): déficit, contextual e participação pública. A motivação principal que delineou a escrita deste trabalho se deve ao fato de que pesquisas na área de ensino de Ciências, com o objetivo de verificar como os recursos audiovisuais estão sendo usados nas aulas de disciplinas científicas do EM identificaram que as principais justificativas para o uso desses recursos, por parte dos professores, estão relacionadas à motivação, ilustração e reforço de conteúdos científicos. Nesse sentido, grande parte do trabalho com DDC em sala de aula se baseia, mesmo que inconscientemente, no modelo do déficit.

Consideramos que o uso da divulgação científica em sala de aula, particularizando aqui os DDC, pode ser realizado tendo em vista os modelos contextuais e de participação pública. Como produto político, histórico e social, os documentários são construídos por meio de uma escolha narrativa e, por conseguinte, ideológica. Os assuntos científicos veiculados por esse tipo de linguagem podem contribuir para reforçar um ponto de vista em detrimento de outro. Em se tratando de DDC, pode acontecer um apagamento desse viés ideológico, pois se espera que a ciência transmitida por esses meios seja detentora da "verdade científica". Sendo assim, salientamos a importância de desenvolvermos atividades tendo em vista os modelos contextuais e de participação pública, principalmente quando nosso objetivo é discutir questões relacionadas à história, natureza da ciência e debates sociocientíficos.

Já que a divulgação científica será o principal meio pelo qual os jovens em idade escolar, e futuros cidadãos, continuarão a "ler" sobre ciência e tecnologia, após sua vida de estudante, atividades tendo em vista os modelos contextuais e de participação pública, objetivam, em última análise, contribuir para a sua alfabetização científica, ao propiciarem momentos de elaboração e discussão baseados em argumentação científica.

Salientamos novamente que atividades dessa natureza podem contribuir para descentralizar o papel do professor como único produtor de significados em sala de aula, ao

2 A versão original desse Guia encontra-se no endereço: http://www.pbs.org/wgbh/nova/education/activities/3213 einstein.html. A versão traduzida pode ser adquirida mediante o envio de e-mail para qualquer um dos autores deste trabalho. 
privilegiar o discurso polêmico entre estudantes e professor. Numa situação tradicional de ensino de disciplinas científicas, prevalece uma visão empírico-positivista de ciência, na qual o professor é apenas um aplicador de técnicas e inovações educacionais (NARDI; CORTELA, 2015). Assim, acreditamos que o papel do professor, ao desenvolver qualquer estratégia de ensino com seus alunos, deve ir ao encontro de modelos mais representativos de sua atuação, por exemplo, como intelectual reflexivo-crítico (GIROUX, 1997). Nesse sentido, o uso de documentários pode representar um espaço de criação para o professor e para os estudantes ao propiciarmos momentos de debate e discussão sobre ciência, tecnologia e suas relações com a sociedade.

\section{REFERÊNCIAS}

A CAVERNA dos sonhos esquecidos. Título original: Cave of forgotten dreams. Diretor: Werner Herzog. Roteiro: Werner Herzog. Intérprete: Werner Herzog. EUA: History Films, 2010 (90 min). Disponível em: $<\underline{\text { https: } / / w w w . y o u t u b e . c o m / w a t c h ? v=I z c r e g Y s l e 4 \& t=14 s}>$. Acesso em: 4 jun. 2017.

ACHIAM, M.; NIELSEN, J. A. Attention to Content: Some Lessons from School-Oriented Education Research. In: AVRAAMIDOU, L., \& ROTH, W. M. (Orgs.). Intersections of Formal and Informal Science. London: Routledge, 2016, p. 33-40.

A EQUAÇÃO de vida e morte Einstein. Título original: Einstein's equation of life and death. Direção: Johanna Gibbon e Aidan Laverty. Intérprete: Jack Fortune. Roteiro: Jeremy Hylton Davies. Reino Unido: BBC Two, 2005 (50 min). Disponível em: $<\underline{\text { http: } / / w w w . ~}$ dailymotion.com/video/xshkn6 einstein-equacao-da-vida-e-morte tech>. Acesso em: 3 jun. 2017.

A GRANDE FARSA do aquecimento global. Título original: The Great Global Warming Swindle. Direção: Martin Durkin. Roteiro: Martin Durkin. London: BBC, 2007 (75 min). Disponível em: $<$ https: $/ /$ www.youtube.com/watch? $\mathrm{v}=$ tpvpiBiuki4\&t=378s $>$. Acesso em: 3 jun. 2017.

A GRANDE IDEIA de Einstein. Título original: Einstein's big idea. Direção: Gary Johnstone. Intérpretes: Andrew Callaway, Andy Crabbe, Daniel D'Alessandro, et al. Roteiro: David Bodanis e Gary Johnstone. Estados Unidos: NOVA, 2005 (120 min).

ALMEIDA, M. J. P. M. Discurso pedagógico e formação de professores de Ciências da natureza: foco no professor de física. Alexandria, v. 5, p. 29-41, 2012. Disponível em: $<\underline{\text { https://periodicos.ufsc.br/index.php/alexandria/article/viewFile/37712/28886 }}>$ Acesso em: 13 jun. 2017. 
. Discursos da ciência e da escola: ideologia e leituras possíveis. Campinas: Mercado das Letras, 2004, 127 p.

. Divulgação científica no ensino escolar: possibilidades e limites. In: GIORDAN, M., \& CUNHA, M. B. (Orgs.). Divulgação científica na sala de aula. Ijuí: Editora UNIJUÍ, 2015, p. 43-66.

. Prescrições e recomendações ao professor na solução de problemas do ensino na educação em Ciências. Ciência \& Ensino, v. 1, n. 1, p. 47-51, 2006. Disponível em: $<$ http://prc.ifsp.edu.br:8081/ojs/index.php/cienciaeensino/article/view/97/97> Acesso em: 13 jun. 2017.

ARROIO, A.; GIORDAN, M. O vídeo educativo: aspectos da organização do ensino. Química nova na escola, v. 24, p. 8-11, 2006. Disponível em: $<$ http://qnesc.sbq.org.br/online/ qnesc24/eqm1.pdf> Acesso em: 13 jun. 2017.

BARBOSA, L. C. A.; BAZZO, W. A. O uso de documentários para o debate Ciência-Tecnologia-sociedade (CTS) em sala de aula. Revista Ensaio, v. 15, n. 3, p. 149-161, 2013. Disponível em: <http://www.scielo.br/pdf/epec/v15n3/1983-2117-epec-15-03-00149.pdf> Acesso em: 13 jun. 2017.

BARCELOS, E. D.; QUILLFELDT, J. A. Onde estão todos os outros? In: Scientific American Brasil. Disponível em: $<\underline{\text { http://www2.uol.com.br/sciam/reportagens/ onde estao to- }}$ dos_os_outros_html $>$. Acesso em: $1^{\circ}$. mai. 2017.

BLOOM, M., BINNS, I. C., \& KOEHLER, C. Multifaceted NOS instruction: contextualizing Nature of Science with documentary films. International Journal of Environmental \& Science Education, v. 10, n. 3, p. 405-428, 2015.

BRUZZO, C. O documentário em sala de aula. Ciência \& Ensino, v. 4, p. 23-25, 1998. Disponível em: < http://prc.ifsp.edu.br:8081/ojs/index.php/cienciaeensino/article/view/32/39> Acesso em: 13 jun. 2017.

BUCCHI, M. Science and the Media: alternative routes in scientific communication. London: Routledge, 1998, 208 p.

BUCCHI, M. Style in Science Communication. Public Understanding of Science, v. 22, n. 8, p. 904-915, 2013.

CABRAL, J. M. P. A radioactividade - contributos para a História da Arte. Lisboa: PRESS, 2011, 312 p.

CHAVES, S. N. História da Ciência Através do Cinema: dispositivo pedagógico na formação de professores de Ciências. Alexandria, v. 5, n. 2, p. 83-93, 2012. Disponível em: 
$<$ https://periodicos.ufsc.br/index.php/alexandria/article/view/37715/28889> Acesso em: 13 jun. 2017.

COMO A CIÊNCIA mudou o nosso mundo? Título original: How science changed our world. Diretor: Sophie Todd. Intérprete: Robert Winston. Produtor: Naomi Austin. Reino Unido: BBC One, 2010 (50 min). Disponível em: $<$ https: $/ /$ www.youtube.com $/$ watch? $v=8 T=$ Szync3X0>. Acesso em: 4 jun. 2017.

DHINGRA, K. Thinking about Television Science: How Students Understand the Nature of Science from Different Program Genres. Journal of Research in Science Teaching, v. 40, n. 2, p. 234-256, 2003.

DIJCK, J. Picturizing science: the science documentary as multimedia spectacle. International Journal of Cultural Studies, v. 9, n. 1, p. 5-24, 2006.

DUSCHL, R. A. Restructuring science education: the importance of theories and their development. New York, London: Teachers College Press, 1990, 155 p.

ESTAMOS SOZINHOS no universo? Título original: Are we alone in the universe? Direção: Gideon Bradshaw. Roteiro: Gideon Bradshaw. Intérprete: Ian Holm. Reino Unido: BBC, 2008 (50 min). Disponível em: <https:/www.youtube.com/ watch? $\mathrm{v}=$ DIWqspQDQAI\&t $=160 \mathrm{~s}>$. Acesso em: 3 jun. 2017.

FALLIK, O., ROSENFELD, S., \& EYLON, B. S. School and out-of-school science: a model for bridging the gap, Studies in Science Education, v. 49, n. 1, p. 69-91, 2013.

FAPESP. Percepção pública da ciência: uma revisão metodológica e resultados para São Paulo. São Paulo, 2005. Disponível em: < file:///C:/Users/User/Downloads/cap12 vol1 2005.pdf> Acesso em: 15 nov. 2018.

FERREIRA, L. N. A., \& QUEIROZ, S. L. Textos de divulgação científica no ensino de Ciências: uma revisão. Alexandria, v. 5, n. 1, p. 3-31, 2012. Disponível em: $<$ https://periodicos.ufsc.br/index.php/alexandria/article/view/37695/28866> Acesso em: 13 jun. 2017.

GALVÃO, C.; REIS, P.; FREIRE, S. A discussão de controvérsias sociocientíficas na formação de professores. Ciência \& Educação, v. 17, n. 3, p. 505-522, 2011. Disponível em:

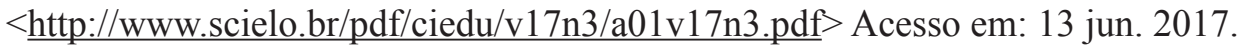

GIROUX, H. A. Os professores como intelectuais: rumo a uma pedagogia crítica da aprendizagem. Porto Alegre: Artmed, 1997, 270 p.

GUERRA, A.; MORAIS, A. História e a filosofia da ciência: caminhos para a inserção de temas física moderna no estudo de energia na primeira série do Ensino Médio. Revista 
Brasileira de Ensino de Física, v. 35, n. 1, p. 1.502-1-1502-9, 2013. Disponível em: <http://www.scielo.br/pdf/rbef/v35n1/v35n1a18.pdf $>$ Acesso em: 13 jun. 2017.

HORVATH, J. E. O ABCD da Astronomia e Astrofísica. São Paulo: Livraria da Física, 2008, 232 p.

JARMAN, R.; MCCLUNE, B. Developing scientific literacy: using news media in the classroom. Maidenhead: Open University Press, 2007, 192 p.

JESUS, R. M. V. Escola e Documentário: uma relação antiga. Revista HISTEDBR, n. 32, p. 233-242, 2008. Disponível em: < http://www.histedbr.fe.unicamp.br/revista/edicoes/32/ art17 32.pdf $>$ Acesso em: 13 jun. 2017.

JIDESJÖ, A. Secondary student's interest in science and technology understood as a media effect. In: XIV IOSTE International Organization for Science and Technology Education, June 13-18 2010, Bled, Slovenia.

KIPNIS, N. Scientific controversies in teaching science: the case of Volta. Science \& Education, v. 10, p. 33-49, 2001.

KLINGER, B. Cave of forgotten dreams: meditations on 3D. Film Quarterly, v. 65, n. 3, p. 38-43, 2012.

LEÃO, R. C. S. Werner Herzog em busca da compreensão humana. Tese (Doutorado em Ciências Sociais) - Departamento de Antropologia, Pontifícia Universidade Católica de São Paulo, São Paulo, 2015.

LEON, B. Science documentaries and their coordinates. Quaderns del CAC, v. 30, p. 11$18,2008$.

LEON, B. Science on Television: the narrative of scientific documentary. Bedfordshire: Pantaneto Press, 2007.

MARANDINO, M. Formação de professores, alfabetização científica e museus de Ciências. In: GIORDAN, M., \& CUNHA, M. B. (Orgs.). Divulgação científica na sala de aula. Ijuí: Editora UNIJUÍ, 2015, p. 111-130.

MCCLUNE, B., \& JARMAN, R. Encouraging and equipping students to engage critically with science in the news: what can we learn from the literature? Studies in Science Education, v. 48, n. 1, p. 1-49, 2012.

McCOMAS, W. The principal elements of the nature of science: dispelling the myths. In: . The nature of science in science education: rationales and strategies. Dordrecht: Kluwer, 2000, p. 53-70. 
MORIN, E. Ciência com consciência. Rio de Janeiro: Bertrand Brasil, 2010, 341 p.

NARASIMHAN, M. G. Controversy in science. Journal of Bioscience, v. 26, n. 3, p. 299304, 2001.

NARDI, R.; CORTELA, B. S. C. Formação inicial de professores de Física em universidades públicas. São Paulo: Livraria da Física, 2015, 354 p.

NASCIMENTO, T. G.; ALVETTI, M. A. S. Temas científicos contemporâneos no Ensino de biologia e física. Ciência \& Ensino, v. 1, n. 1, p. 29-39, 2006. Disponível em: $<$ http://prc. ifsp.edu.br:8081/ojs/index.php/cienciaeensino/article/view/36/95> Acesso em: 13 jun. 2017.

NICHOLS, B. A voz do documentário. In: RAMOS, F. P. Teoria Contemporânea do Cinema - documentário e narratividade ficcional. São Paulo: SENAC, 2005.

NICHOLS, B. Introduction to documentary. Bloomington: Indiana University Press, 2010, $368 \mathrm{p}$.

O ÁTOMO. Título original: Atom. Direção: Tim Usborne. Intérprete: Jim All-Khalili. Produtor: Martin Davidson e Paul Sen. Reino Unido: BBC, 2007 (150 min). Disponível em:

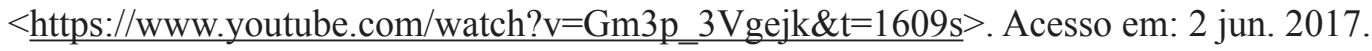

O UNIVERSO elegante. Título original: The elegante universe. Direção: Joseph McMaster, David Hickman e Julia Cort. Intérprete: Brian Greene. Produtor: Julia Cort, Brian Greene e Joseph McMaster. Produtor: Paula Apsell, et al. Estados Unidos/Reino Unido: BBC e PBS NOVA, 2003 (180 min). Disponível em: $<$ https://www.youtube.com/ watch? $\mathrm{v}=053 \mathrm{Wje} 5 \mathrm{f} 72 \mathrm{I} \& \mathrm{t}=56 \mathrm{~s}>$. Acesso em: 2 jun. 2017.

PEREIRA, A. A. G. O Documentário de Divulgação Científica e a discussão de aspectos da Física Moderna e Contemporânea na Formação Inicial de Professores de Física, 241s. Tese (Doutorado em Ensino de Ciências e Matemática) - Instituto de Física "Gleb Wataghin", Universidade Estadual de Campinas, Campinas, 2017.

PEREIRA, A. A. G.; ALMEIDA, M. J. P. M. O documentário A caverna dos sonhos esquecidos: atividades na formação de professores de física. Comunicação \& Educação, v. 22, n. 2, p. 49-63, 2017.

PRAIA, J.; PÉREZ, D. G.; VILCHES, A. O papel da natureza da ciência na educação para a cidadania. Ciência \& Educação, v. 13, n. 2, p. 141-156, 2007. Disponível em: $<\underline{\text { http:// }}$ www.scielo.br/pdf/ciedu/v13n2/v13n2a01.pdf> Acesso em: 13 jun. 2017.

RAMOS, M. B. Na pauta das aulas de Ciências: discussão de controvérsias científicas na televisão. Tese (Doutorado em Ensino e História de Ciências da Terra) - Instituto de GeoCiências, Universidade Estadual de Campinas, Campinas, 2010. 
. \& SILVA, H. C. Educação em ciência e em audiovisual: olhares para a formação de leitores de Ciências. Cadernos CEDES, v. 34, n. 92, p. 51-67, 2014. Disponível em: $<$ http://www.scielo.br/pdf/ccedes/v34n92/a04v34n92.pdf $>$ Acesso em: 13 jun. 2017.

. SILVA, H. C. Para pensar as controvérsias científicas em aulas de Ciências. Ciência \& Ensino, v. 1, p. 1-16, 2007. Disponível em: $<$ http://prc.ifsp.edu.br:8081/ojs/index. php/cienciaeensino/article/view/132/106> Acesso em: 13 jun. 2017.

REID, G. The television drama-documentary (dramadoc) as a form of science communication. Public Understanding of Science, v. 1, p. 1-18, 2011.

REID, G.; NORRIS, S. P. Scientific media education in the classroom and beyond: a research agenda for the next decade. Cultural Studies of Science Education, v. 11, p. 147166, 2016.

REZENDE, L. A. História das Ciências no ensino de Ciências: contribuições dos recursos audiovisuais. Ciência em Tela, Rio de Janeiro, v. 1, n. 2, p. 1-7, 2008. Disponível

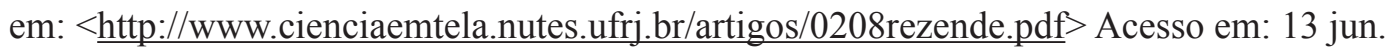
2017.

REZENDE, L. A. C., PEREIRA, M. V., \& VAIRO, A. C. Recursos audiovisuais como temática de pesquisa em períodicos brasileiros de Educação em Ciências. Revista Brasileira de Pesquisa em Educação em Ciências, v. 11, n. 2, p. 183-204, 2011. Disponível em: $<\underline{\text { ht- }}$ tps://seer.ufmg.br/index.php/rbpec/article/viewFile/2406/1806> Acesso em: 13 jun. 2017.

SANTOS, P. C., ARROIO, A. A utilização de recursos audiovisuais no ensino de Ciências: tendências nos Enpecs entre 1997-2007. In: Encontro Nacional de Pesquisa em Educação em Ciências, 12. Anais... Florianópolis: Abrapec, 2009, p. 1-12. Disponível em: $<\underline{\text { http:// }}$ posgrad.fae.ufmg.br/posgrad/viienpec/pdfs/649.pdf> Acesso em: 13 jun. 2017.

SCHEUFELE, D. A., \& LEWENSTEIN, B. V. The public and nanotechnology: How citizens make sense of emerging technologies. Journal of Nanoparticle Research, v. 7, p. 659-667, 2005.

SE A CLONAGEM pudesse nos curar. Título original: If...cloning could cure us. Direção: Mary Downes. Intérprete: Dr. Alex Douglas. Produção: Peter Morgan. Roteiro: Sutton J. London: BBC Two, 2004.

SILVA, W. M.; VELASCO, P. D. N.; ZANOTELLO, M. O debate na perspectiva da lógica informal: uma abordagem para análise da argumentação em aulas de Ciências. Revista Ensaio, v. 8, n. 2, p. 99-127, 2016. Disponível em: $<$ http://www.scielo.br/pdf/epec/ v18n2/1983-2117-epec-18-02-00099.pdf $>$ Acesso em: 13 jun. 2017. 
STURGIS, P.; ALLUM, N. Science in society: re-evaluating the deficit model of public attitudes. Public Understanding of Science, v. 13, n. 1, p. 55-74, 2004.

TAVARES, D. Audiovisual e ciência na sala de aula: Por um "espírito artístico e emoção científica”. In: GIORDAN, M., \& CUNHA, M. B. (Orgs.). Divulgação científica na sala de aula. Ijuí: Editora UNIJUÍ, 2015, p. 87-110.

TERRAZAN, E. A. Inovação escolar e pesquisa sobre formação de professores. In: NARDI, R. A pesquisa em ensino de Ciências no Brasil: alguns recortes. São Paulo: Escrituras Editora, 2007.

UMA VERDADE Inconveniente. Título original: An Inconvenient Truth. Direção: Davis Guggenheim. Intérprete: Al Gore. Produção: Al Gore. Roteiro: Lawrence Bender, Scott Burns, Laurie Lennard e Scott Z. Burns. 2006. 1 DVD (100 min). Disponível em: $<\underline{\text { https:// }}$ www.youtube.com/watch? $v=X 3$ wry4u9eFA\&list $=$ PLEFFsWi75F6ACcwsCliuy8Qp0b2K

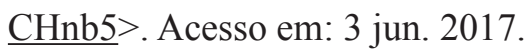

\section{Dados dos AUtores:}

\section{Aldo Aoyagui Gomes Pereira}

Doutor em Ensino de Ciências e Matemática pela Universidade Estadual de Campinas. Professor no Instituto Federal de Educação, Ciência e Tecnologia (IFSP) - campus Piracicaba. Piracicaba/SP - Brasil. agpereira980542@gmail.com

Silmara Rodrigues Domingues

Mestranda no Programa de Pós-Graduação em Ensino de Ciências e Matemática (PECIM) da UNICAMP. Membro do Grupo de Pesquisa FORMAR Ciências da Faculdade de Educação da UNICAMP. Piracicaba/SP - Brasil. silmara1945@gmail.com

\section{Aline Rodrigues de Carvalho}

Licenciada em Física no Instituto Federal de Educação, Ciência e Tecnologia - campus Piracicaba (2018). Bolsista do Programa Institucional de Bolsa de Iniciação à Docência (PIBID). Piracicaba/SP - Brasil. carvalhoraline@yahoo.com.br

Submetido em:13-6-2017

Aceito em: 7-12-2018 